Araştırma Makalesi- Research Article

\title{
Uzun Kemik Kırıkları İçin Yeni Bir Sabitleyici Çivi Geliştirilmesi
}

\begin{abstract}
Mustafa Soylak $^{1 *}$
Geliş / Received: 19/04/2020

Kabul / Accepted: 08/06/2020

ÖZ

İnsan vücudunda femur, tibia ve humerus isimleri ile adlandırılan büyük ve uzun kemikler bulunmaktadır. Bu kemikler bazı istenmeyen olaylar sonucu oluşan ani darbe etkileri ile kırılmakta ve tedavi süreçleri son derece riskli süreçler olarak karşımıza çıkmaktadır. Tüm bu kemiklere ait kırılmalarda tedavinin en önemli bölümü kırık kemiklerin kaynama sağlanana kadar sabitlenmesidir. Kırık kemiklerin tedavi sürecinde sabitlenmesi konusunda bir çok sistem geliştirilmiştir. İnsan vücudunda bulunan büyük ve uzun kemiklerin tedavi süreci boyunca sabitlenmesi konusunda en önemli yöntem intramedüller kilitleme yöntemidir. Bu yöntemde kemik içi boşluğa yerleştirilen ve farklı noktalarında bulunan vida deliklerinden vidalama yapılarak kırık kemiklerin sabitlenmesini sağlayan bir çivi kullanılmaktadır. Bu yöntemle alakalı mevcut teknolojiler incelendiğinde bir çok olumsuzluklarla karşılaşıldığı tespit edilmiştir. Bu çalışma kapsamında tamamen özgün ve yeni bir intramedüller kilitleme sistemi geliştirilmiş, 3 boyutlu modellemesi yapılmış, çalışma ilkeleri ve sağladığı kazanımlar açıklanmıştır.
\end{abstract}

Anahtar Kelimeler- Intramedïller Kilitleme, Çivi, Ortopedi, Kurık Tedavisi

Sorumlu yazar iletişim: soylakm@erciyes.edu.tr (https://orcid.org/0000-0002-5617-5913)

Mekatronik Lab., Havacılık ve Uzay Bilimleri Fakültesi, Erciyes Üniversitesi, Kayseri, Türkiye 


\title{
Development of a New Fixing Nail for Long Bone Fractures
}

\begin{abstract}
There are large and long bones in the human body called femur, tibia and humerus. These bones are broken with sudden impact effects caused by some undesirable events and treatment processes appear as extremely risky processes. The most important part of the treatment in all these bone fractures is to fix the broken bones until boiling is achieved. Many systems have been developed to fix broken bones in the treatment process. The most important method for fixing the big and long bones in the human body during the treatment process is intramedullary locking method. In this method, a nail is used which is placed in the bone cavity and which is used to fix the broken bones by screwing through the screw holes located at different points. When the existing technologies related to this method are examined, it is determined that many negativities are encountered. Within the scope of this study, a completely original and new intramedullar locking system has been developed, 3D modelling has been made, the working principles and the gains have been explained.
\end{abstract}




\section{GİRIŞ}

İnsan vücüdunda femur, tibia ve humerus isimleri ile adlandırılan büyük ve uzun kemikler bulunmaktadır. Femur, kalça ekleminden başlamakta diz ekleminde sona ermekte ve uyluk kemiği ismiylede anılmaktadır. Diz ile ayak bileği arasında bulunan kemiklere ise Tibia adı verilmektedir. Diğer büyük boyutlu kemik ise humerus isimli kemiktir ve omuz ile dirsek arasında yer almaktadır (Şekil 1).

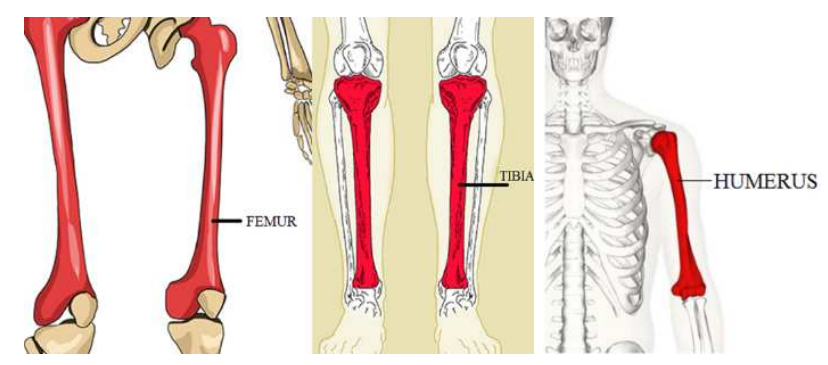

Şekil 1. İnsan Vücudunda Bulunan Büyük Kemikler [1,2,3]

Bu kemikler bulunduğu yere ve yaptığı işe göre farklı sebeplerle kırılmaktadırlar. Bu sebeplerden bazıları;

- $\quad$ Direkt darbeler

- Aşırı zorlanmalar

- Düşme

- Trafik kazaları

- Ateşli silah yaralanmaları,vb.

şeklinde sıralanabilir. Bu durumlarda oluşan sonuçlardan bazıları Şekil 2' de verilmiştir.

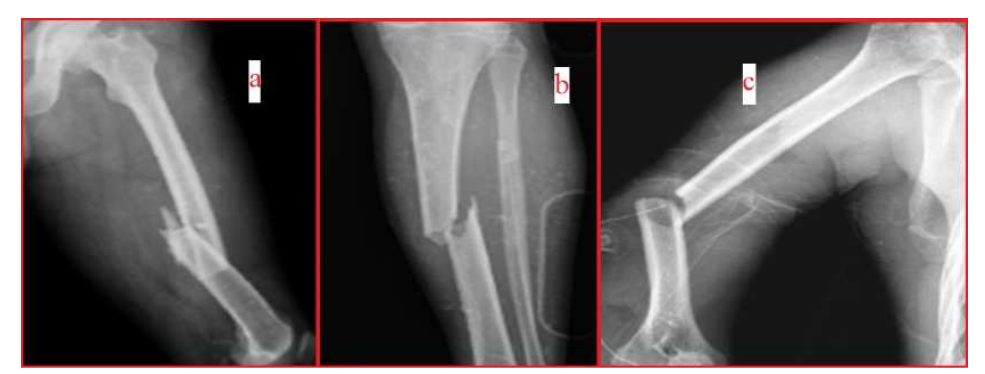

Şekil 2. Büyük kemiklerde oluşan kırıklar (a: Femur, b: Tibia, c:Humerus) [4]

Kırık bölgesinde yapılan radyolojik muayene sonrasında tedavi yöntemine karar verilmektedir. Hangi sebeple olursa olsun öncelikli olarak kırıkla tedaviye gelen hastanın operasyonla kemiğinin sabitlenmesi ve kemik kaynama sürecinde sabit kalması gerekmektedir. Bu tedavi yöntemleri kimi zaman alçı, atel vb. yöntemlerle gerçekleştirilirken bazı durumlarda ise vidalanan plaklar ve/veya intramedüller çivi tedavileri uygulanmaktadır. İntramedüller çivi uygulamasında kırık yerini açarak yada hiç açmadan sabitleyici tüp şeklinde parçanın kemik içine takılması ile kırık bulunan kemiğin sabitlenmesi sağlanır. Bu sabitlemenin sağlanabilmesi için kemik içi boşluğa bir çivi yerleştirilmekte ve bu çivi mevcut durumda kemiğe vidalanarak sabitlenmektedir. 
Kemik içine takılan bu komponentin kalacağı süre birkaç aydan ömür boyu sürecek kadar uzayabilmektedir (Şekil 3).

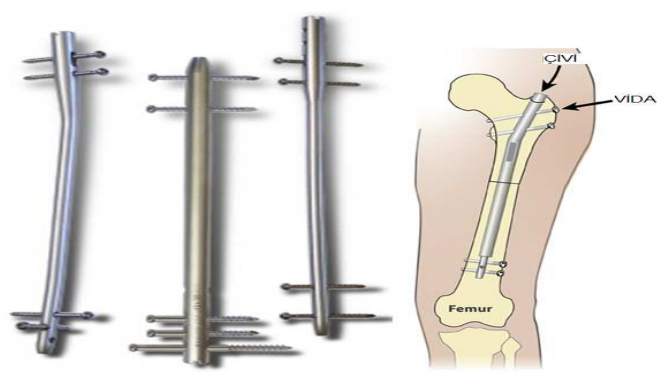

Şekil 3. İntramedüller kilitleme [3,5]

İntramedüller kilitleme çok yaygın şekilde kullanılan bir tedavi yöntemidir. Bu tedavi yönteminin uygulanması esnasında yaşanan en büyük problem: kemik içine yerleştirilmiş bir çivi üzerinde bulunan deliklerin ameliyathane ortamında kemik ve doku dışından algılanabilmesi ve bu deliklere vidalama yapılarak sabitleme işleminin gerçekleştirilebilmesidir. Mevcut intramedüller kilitleme teknolojilerinde, uygulama gerçekleştiren cerrah ve ekibinin tüm süreçte yoğun radyasyona maruz kaldığı, çok fazla tecrübe gerektiren, hasta üzerinde yoğun kesi oluşmasına sebep olan yöntemler yaygın şekilde kullanılmaktadır. Bu problemlerin giderilmesi veya en aza indirilebilmesi ve sistemin daha hızlı, güvenilir, kolay uygulanabilir olması ve böylece operasyon süresinin kısaltılarak ameliyathanede bulunan ekibin daha az radyasyona tabi kalması, hastanın daha az kesiye maruz kalması ve sürecin kolaylığı yönünde bilimsel çalışmalar yapılmaktadır. Bu tedavi yöntemi aynı zamanda bir çok mesleki disiplinin ortak çalışmasını gerektiren çok disiplinli bir araştırma konusu olarak karşımıza çıkmaktadır. İntramedüller çivi uygulaması esnasında ilk çivileme deliğini bulmayı distal kilitleme deliklerini 3,5-5 cm. arasında tasarlayarak kolaylaştıran bir sistem araştırmacılar tarafından geliştirilmiş olup, ilk vidayı en az hata ve olabilen en az skopi kullanımı ile tespit edebilen bu çalışmada, cerrahi ekip ilk uygulanan vidayı referans alarak kalan vidaları tatbik edebilmektedir [6]. Bir başka araştırmacı gurubu ise mevcut teknolojileri incelemişler, karşılaştırmalı şekilde değerlendirmelerde bulunmuşlardır [7]. Intramedüller çivi uygulamasının biomekanik avantajları olduğu ve bu özelliğine ilave olarak erken sürede hareket etmeye izin verdiği, yüksek kırık iyileşme oranlarına sahip olduğu, düşük enfeksiyon riski taşıdığı için diğer tedavi seçeneklerinden daha üstün olduğu araştırmacılar tarafından gerçekleştirdikleri çalışmalarda belirlenmiştir. Mevcut tüm teknolojiler içinde farklı uzun kemik kırı̆̆ı tedavileri açısından en iyi yönetmin intramedüller çivi sistemi olduğunu vurgulayan çok sayıda araştırma bulunmaktadır [8-15]. Bir diğer çalışmada araştırmacılar genişleyebilir intramedüller çivileri incelemişler ve günümüzde kullanılan tekniklerin olumlu özelliklerinden hareketle tasarlanıp geliştirildikleri tespitinde bulunmuşlardır. Kemik içine oymadan yerleştirilebilmesi ve daha az cerrahi müdahale gereksinimi olması, stabil kalabilme özelliği, daha az skopi kullanımı, kanlanmaya en düşük düzeyde zarar verme özelliği, uygulanabilirliğin daha kolay olması ve ameliyat süresini kısaltması gibi avantajları öngörülmüştür. Femur cisim kırıklarında genişleyebilir intramedullar çivi uygulamalarının fonksiyonel ve radyolojik sonuçları araştırmacılar tarafından incelenmiş, genişleyebilir intramedüller çivilerde yeterli stabilite sağlanamadığı durumlar olduğu tespit edilmiş [16]. Tüm zorluklarına ragmen uzun kemik kırıklarında intramedüller çivilerin cerrahi tedavide ilk seçenek olduğunu belirten araştırmacılar çok sayıdadır [16-20]. Bu çalışmada mevcut tüm intramedüller çivilerden farklı olan, tamamen mekanik çalışan, uygulama esnasında yaşanan sorunları ortadan kaldıran yeni bir sistem geliştirilmiştir. Bu sisteme ait çalışma yapısı, sağladığı kazanımlar ve süreçte beklenen gelişmeler açıklanmıştır.

\section{MATERYAL VE METOD}

İntramedüller çivileme sistemleri uzun kemik kırıklarında en önemli tedavi yöntemi olarak karşımıza çıkmaktadır. Ancak mevcut teknolojiler incelendiğinde 5 temel başlık altında toplayabileceğimiz problemlemler olduğu tespit edilmektedir;

1. Çivi üzerinde bulunan sabitleme delik yerlerinin ameliyat ortamında tespit edilme zorluğu, 


\begin{tabular}{|c|c|c|}
\hline & $\begin{array}{l}\text { BŞEÜ Fen Bilimleri Dergisi } \\
7(1), 363-369,2020\end{array}$ & $\begin{array}{r}\text { BSEU Journal of Science } \\
\text { DOI: } 10.35193 / \text { bseufbd. } 723422\end{array}$ \\
\hline $\begin{array}{l}\mathrm{E} \\
\mathrm{R}\end{array}$ & & 88-7575 (http://dergipark.gov.tr/bseufbd) \\
\hline
\end{tabular}

2. Uygulama esnasında cerrahi ekibin ve hastanın maruz kaldığı radyasyon süresinin ve miktarının fazlalığı,

3. Çok fazla kesi yapılması gerekliliği,

4. Çok fazla operator tecrübesi gereksinimi,

5. Tedavi oluştuktan sonra çivinin bulunduğu yerden çıkarılması esnasında oluşan enfeksiyon riski.

Özellikle kemik içine yerleştirilen çivi üzerinde bulunan sabitleme deliklerinin ameliyathane ortamında iken kilitleme esnasında tespiti son derece zor ve bazen imkansız olabilmektedir. Çalışma kapsamında tamamen mekanik bir tasarım geliştirilmiş ve kemik içine yerleştirilen çivinin sabitlenmesi sağlanmıştır. Geliştirilen sistemde herhangi bir vidalama işlemi yapılmamaktadır. Kilitleme işlemi için uygulanan kuvvet sahip olduğu mekanizma ile ayarlanabilmektedir. Süreç sonunda çivinin yerinden çıkarılması veya herhangi bir müdahale gerekmesi durumunda geliştirilen sistem mevcut tüm tasarımlardan daha kolay ve kısa sürede müdahale imkanı vermektedir (Şekil 4).

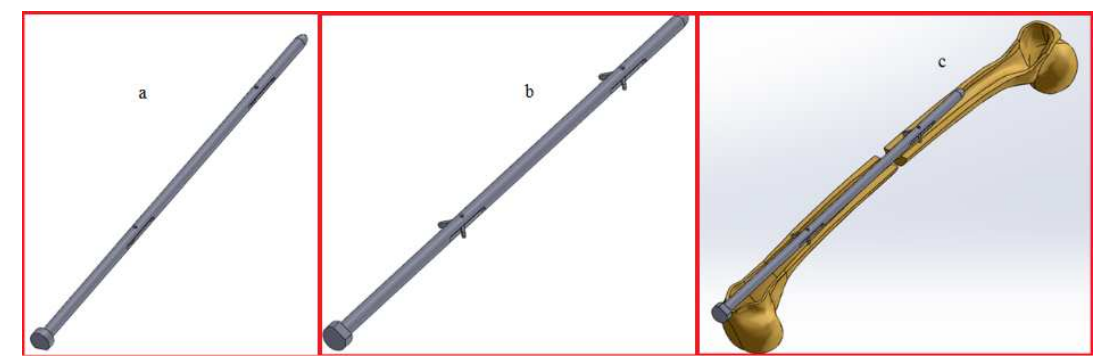

Şekil 4. Distal kilitleme Mekanizması Çalışma sistemi (a: Kapalı Durumda, b: Açık durumda(torklanmış), c:Kemik İçi Sabitleme İşlemi Yapılmış)

Çalışma kapsamında geliştirilen intramedüller kilitleme sistemi ile çalışılırken; öncelikli olarak çalışma kapsamında geliştirilen sabitleme çivisi kemik içine yerleştirilmekte ve sabitleme öncesi konumlaması yapılmaktadır. Tork uygulama başlığı vasıtası ile ayarlanabilir tork kolu kullanılarak vida sıkma yönünde çevrilmektedir. Çivi içinde dönme hareketi yapan vidaya takılı olan somun görevi gören parka kemik uzunlama ekseni boyunca lineer hareket yapmakta ve bu esnada somuna entegre edilmiş olan sıkma başlıkları kemik içinde tutmayı sağlayacak $\alpha$ açısal değeri kadar açılmaktadır. Sökme esnasında ise bu süreç tam tersi yönde gerçekleştirilmektedir. Bu açısal hareket sonucunda kemik üzerinde kilitlemeyi sağlayan bir baskı kuvveti (Fn) oluşmakta ve çivinin kemik içinde sabitlenmesi gerçekleşmektedir (Şekil 5).

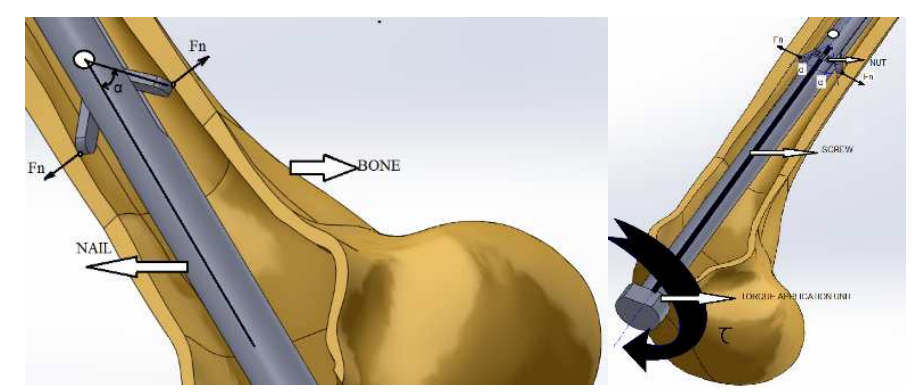

Şekil 5. Geliştirilen intramedüller çivi sistemi

Bu esnada uygulanan tork $(\tau)$ ile kemik yüzeyine uygulanan kuvvet (Fn) arasındaki ilişki çalışmanın deneysel uygulamaları ve kadavra çalışmaları gerçekleştirildikten sonra net tanımlı hale gelebilecektir. Ancak, tüm kuvvet ve tork değerlerinin ayarlanabilir olması sistemin önemli bir kazanımı ve esnek yapısı olarak görülmektedir. Çalışma kapsamında geliştirilen intramedüller çivileme sistemi sayesinde; 
1. Hastanın ve ameliyat ekibinin hiç veya en az seviyede radyasyona tabi kalması,

2. İşlem sürecinde önemli oranda kısalma ve hastanın daha az anestezi alması,

3. Daha az cerrahi operasyon ve daha az kesi ile operasyonun gerçekleşmesi sayesinde daha kısa iyileşme süreci,

4. Daha az enfeksiyon riski,

5. Daha az operatör tecrübesi ve kolay kullanım imkanları elde edilebilmektedir.

\section{SONUÇLAR}

$\mathrm{Bu}$ çalışmada literatürde bulunmayan tamamen yeni bir intramedüller çivi sistemi geliştirilmiştir. Geliştirilen sistemin 3D modellemesi yapılarak çalışma yapısı açıklanmıştır. Çalışma kapsamında geliştirilen sistemin mevcut sistemlerden yaygın kullanımı olanlar ile karşılaştırması yapılarak avantajlı yönleri belirtilmiştir. Geliştirilen sistemin ayarlanabilir kuvvet kontrolü sağlayan ve en az kesi ile oprasyonu gerçekleştirme imkanı veren kilitleme mekanizması sayesinde ilgili konu hakkında çok önemli kazanım sağlayacağı tespit edilmiştir. Çalışmanın ilerleyen aşamasında prototip geliştirilecek, gerekli izin süreçleri sonrası deneyler yapılarak, kilitleme noktaları ve bu kilitleme işlemlerinde kullanılan yüzey formları ile ilgili alternatifler belirlenecektir. Ayrıca, uzun kemiklerin sahip oldukları eğim ile ilgili oluşturulacak alternatif hareket aktarım yöntemleri incelenecektir. Bu alternatif durumlar arasında esnek malzeme ile güç aktarımı sağlanması, kilitleme noktası sayısının arttırılması, kilitleme noktası konumlarının farklılaştırılması ve kilitleme bölgesinde tutunmayı arttıracak farklı yüzey formlarının uygulanması bulunmaktadır.

\section{KAYNAKLAR}

[1] Mammoth Memory Web Page (2020). https://mammothmemory.net/biology/skeletons-and-bones/skeletonand-bones/femur.html

[2] Teach Me Anatomy Web Page (2020). https://teachmeanatomy.info/upper-limb/bones

[3] Medimetal Medical Products Manufacturing and Trading Ltd. Web Page (2020). http://www.medimetal.hu/en/surgical-systems/tibia-femur-retr-femur-

[4] Prof. Dr. Mehmet Subaş1 (Ortopedi, ve Travmatoloji Uzmanı) Web Sayfası (2020). https://drmehmetsubasi.com/ortopedik-travma-humerus-kiriklari-16.html

[5] International Center for Limb Lengthening (Rubin Institute for Advanced Orthopedics) Web Page (2020). http://www.limblength.org/treatments/lengthening-deformity-correction-devices/internal-fixation-rods-andnails/

[6] İmiroğlu, H.İ., et.all.(2014). Skopi kullanımı gerektirmeyen intramedüller distal kilitleme sistemi: yeni bir cihaz. Süleyman Demirel Üniversitesi Mühendislik Bilimleri ve Tasarım Dergisi, 2:3, 189-198.

[7] Rosa, N., et.all. (2019). Intramedullary nailing biomechanics: Evolution and challenges. Proceedings of the Institution of Mechanical Engineers, Part H: Journal of Engineering in Medicine, 233:3, 295-308.

[8] Chapman, MW. (1996). The role of intramedullary nailing in fracture management. In: The Science \& Practice of Intramedullary Nailing, Browner DB (ed), 2nd edition, Williams \& Wilkins, Philadelphia, 27-38.

[9] Bucholz. RW., Brumback. RJ. (1996). Fractures of the Shaft of the Femur. In:Rockwood and Green's Fractures in Adults, Rockwood CA, Green DP(ed.), Lippincott-Raven Publishers, Philadelpia, 1827-1918.

[10] Gausepohl, T., et.all. (2002). Anterograde femoral nailing: an anatomical determination of the correct entry point. Injury, 33,701-705.

[11] Harper, MC., Carson, WL. (1987). Curvature of the femur and the proximal entry point for an intramedullary rod. Clin Orthop, 220,155-161.

[12] Steriopuolos, K., et. all. (1997). Architecture of the femoral medullary canal and working length for intramedullary nailing. Acta Orthop Scand ,68,123-126. 
[13] Zuber, K., et. all. (1988). Form and dimension of the bone marrow cavity of the human femur with reference to the fit of intramedullary implants. Unfallchirurg, 91, 314-319.

[14] Harma, A., et.all. (2005). The comparison of femoral curves and curves of contemporary intramedullary nails. Surg Radiol Anat, 27, 502-506.

[15] Portakal, S., et.all. (2004). Kapalı Femur Cisim Kırıklarında Oymalı (Reamed) Teknikle Kilitli İntramedüller Çivileme ve Prospektif Degerlendirme Sonuçları. Hr.U.Tıp Fak. Der., Sayı:2.

[16] Atay, T., et.all.(2008). Femur Diafiz Kırıklarında Genişleyebilir İntramedüller Çivi Sonuçlarımız. Kocatepe Tip Dergisi The Medical Journal of Kocatepe, 9, 11-15.

[17] Farouk, O., et.all. (1997). Minimally invasive plate osteosynthesis and vascularity: preliminary results of a cadaver injection study. Injury,28:1, 7-12.

[18] Krettek,C., et.all.(1997). New developments in stabilization of dia- and metaphyseal fractures of long tubular bones. Orthopade, 26, 408-21.

[19] Egol, KA.(2004). Minimally invasive orthopaedic trauma surgery: a review of the latest techniques. Bull Hosp Jt Dis., 62, 6-12.

[20] Apivatthakakul, T.(2007). Humerus, shaft. In: Tong GO, Bavonratanavech S, editors. AO Manual of fracture management, minimally invasive plate osteosynthesis (MIPO). New York: Thieme,p. 145-73. 